\title{
Fatima Pictures and Testimonials: in-depth Analysis
}

\author{
PHILIPPE DALLEUR \\ Pontifical University of the Holy Cross, Rome \\ dalleur@pusc.it
}

ORCID: 0000-0002-2448-1190

\begin{abstract}
Using photographs and testimonials, we will analyze details of the "miracle of the spinning sun" on October 13,1917, at solar noon near Fatima. The phenomenon predicted ahead of time, occurred as the clouds cleared on what began as a rainy day. Various explanations have been presented but do not stand up to a comparative analysis of eyewitnesses (up to $35 \mathrm{~km}$ away), weather data, and photographs. This article aims at bringing clarity to this event through the analysis of certified photographs and testimonies compared with official meteorological and astronomical data. Our study confirms key points of the testimonials while focusing on objective data. The shadows and reflections reveal two soft light sources emerging from a rather dark background: one seen as a "pale sun", and another overhead, fuzzy and as softly bright. The latter, likely being caused by a clear cloud, blurred the shadows of the weak "sun". Strangely, the portions of clothing exposed to this "sun" dried quickly. This warm source, uncannily moonlike, was also able to cast distinct shadows on sloping surfaces and under objects. Eventually, these shadows will help us to estimate the height of the "sun" at $~ 30^{\circ}$, lower than the expected $42^{\circ}$. Therefore, the directly observed source could not have been the sun, and most probably not any physiological, psychological, or meteorological effect.
\end{abstract}

Keywords: apparition; miracle; skepticism; illusion; photography; parhelia. 


\section{Introduction}

A surprising event took place on October 13, 1917, at solar noon in Portugal. A crowd estimated between 30,000 and 100,000 people had gathered at the Cova da Iria, north of Fatima, to witness a "miracle”. This was previously announced on July 13, 1917, although its nature was not revealed. The crowd was made up of people holding all philosophical convictions and religious conditions. The Catholic Church asked its priests not to go (Barthas 1957, 199), fearing an antireligious setup intended to ridicule the Church, in a country governed by an anticlerical regime from 1910 .

Since 1917, the great diversity of explanations shows how diverse the scientific and cultural community is: each group pushes forward its own story, not being convinced by others, showing the weakness of the arguments and their lack of credibility (Archbold 2016; Haffert 2006, 78-81; van den Aardweg 1988, 22-30). In cases like Fatima, secular science has a trivializing and reductionist bias, that hides key differences and details behind common comparable events. But comparison is not reason enough. This reductionist line inhibits thorough investigations. Fatima seems to be one of the worst scientifically explained phenomena, driven by ideologies and prejudices: dancing or vibrating suns, sundogs, plasma vortex, atmospheric lens or ice reflections, volcanic or Sahara dust, unusual auroras, retinal phosphenes or fatigue, brain illusions, collective hallucinations, mass suggestions or hysteria, UFOs, deception, setup story, lies, etc. Our analysis will confront most of those explanations with in-depth data analysis. We will not add new possible explanations. This article aims at bringing more clarity to this event. We performed through the analysis of certified photographs and testimonies and compared them to official meteorological and astronomical data. In particular, we criticize recent conjectures (Campbell 1989; Jaki 1999; Meessen 2005; Simons 2005; Radford 2013; 2019; Wirowski 2012; 2019), which do not stand up to a comparative analysis of witnesses, weather data, and photographs. 
Eyewitness Gonçalo Xavier de Almeida Garrett ${ }^{1}$, professor of mathematics at Coimbra University, summed up his factual testimony on December 3, 1917:

$1^{\circ}$ The phenomenon lasted about 8 to 10 minutes;

$2^{\circ}$ the sun lost its blinding brightness, taking on a moonlike glow easy to watch;

$3^{\circ}$ for three times during this event, the sun appeared gyrating in its periphery, flashing sparks of light on its edges, as the well-known firework wheels;

$4^{\circ}$ this circling movement of the edges of the sun, three times manifested and interrupted, was speedy [...];

$5^{\circ}$ the sun turned violet and then orange, spreading these colors over the earth, regaining its shine and brightness, impossible to gaze;

$6^{\circ}$ these facts happened shortly after noon and near the zenith (that is very important) [...]

I do not consider the phenomena observed in the sun, as astronomical [...] but as atmospheric over the solar image, with moonlike and spin effects. Those effects however, are unbelievable to occur at noon and at the zenith, when meteorological effects are weak [...] It's tough to produce these phenomena by noon. (Coelho and dos Santos 2013, 146-147)

Thanks to the kind collaboration of the Archives of the Sanctuary of Fatima, we analyzed six high-resolution photographs ${ }^{2}$ (see Fig. 1), directing our indepth analysis to picture D115, for the briefness of the article. Together with certified meteorological data, the pictures allow us to confirm a majority of testimonials, in particular:

$1^{\circ}$ the event happened during an unexpected clearing in a cloudy and rainy sky;

1 Coimbra University keeps two of his works on solar astronomy: The Question of the Intra-mercury Planets (1869; Einstein's theory of general relativity later explained the studied anomalies of Mercury's solar orbit) and Study on the fixed Plane of the Solar System (1870), accessible at http://webopac.sib.uc.pt/. Garrett witnessed solar eclipses and was well aware of the eye pathologies that should be avoided. On page 17 of the first study, he presents his rigorous scientific methodology based on observations in order to establish theories. His son Jose Maria Garrett, former professor of Law at the same University and also present at the Cova da Iria, gave the most precise description of the event (see below).

2 About 27 million pixels per black and white (BW) picture with 1300 dpi estimated resolution for the European standard $12 \times 9 \mathrm{~cm}$ negative plates. 


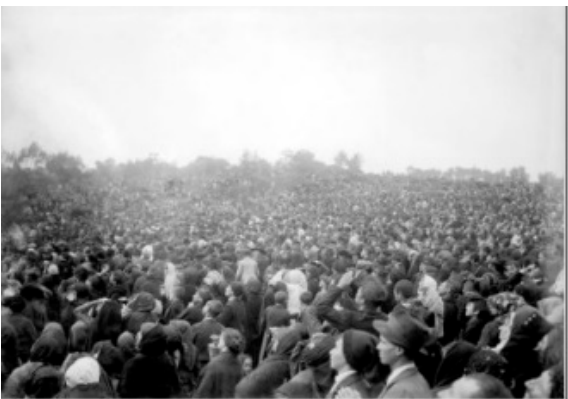

D110.tif

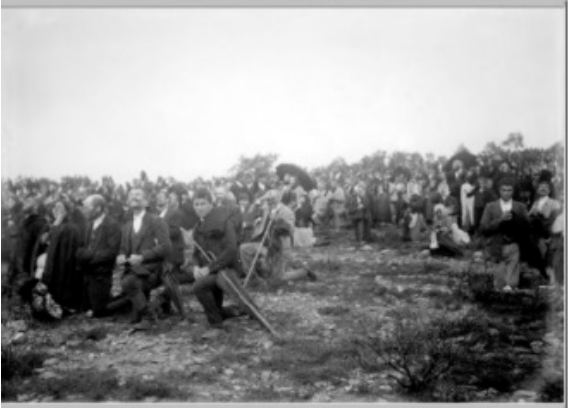

D114.tif

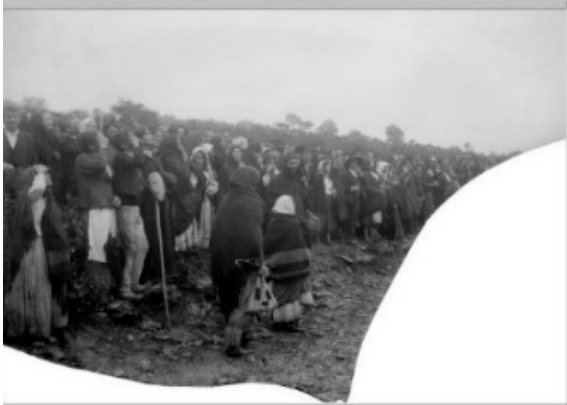

D116.tif

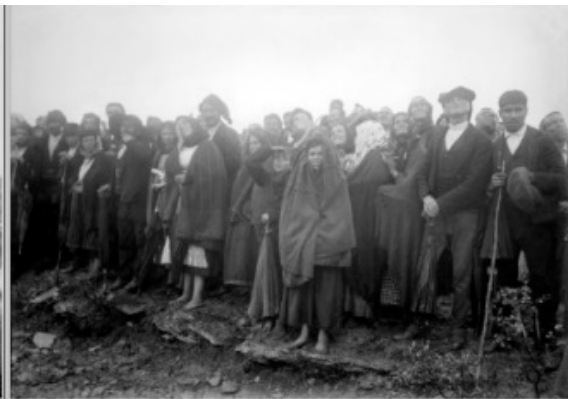

D113.tif

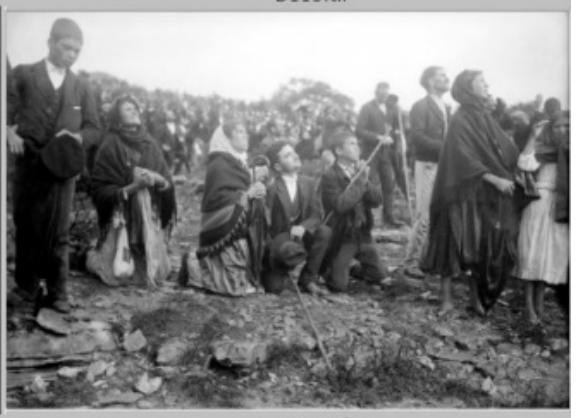

D115.tif

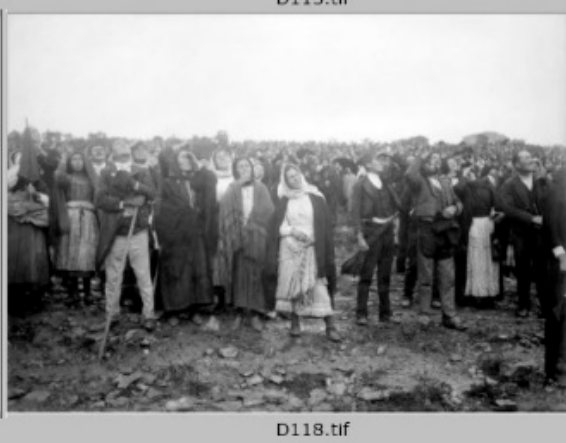

Figure 1. Analyzed photographs, 6K accuracy - @ A Arquivo do Santuário de Fátima. See less precise versions at https://www.fatima.pt/pt/multimedia/images/19171013 (accessed on Nov. 12, 2020) 
$2^{\circ}$ the main light source identified as the sun by many (we call it $L S a-$ Light Source $a$ - to avoid confusion; see Haffert 2006, XIX, 15), was pale, but strangely distinct and warm, able to fast dry wet clothes;

$3^{\circ} L S a$ was seen in the sun's direction and merging with it, at least at the end;

$4^{\circ}$ the location, day, and time of the event was announced three months before;

$5^{\circ}$ this explains the presence in the photos of a large crowd of all conditions, and the press media, in this forgotten backwater despite the gloomy weather.

We will also study the pictures discernible shadows and reflections, to help identify the sky brightness map, showing a second main light source $L S b$, probably some clear cloud overhead, and eventually estimate the elevation angle of $L S a$.

\section{October 13, 1917: weather in Fatima}

In two articles, Benjamin Radford (2013; 2019), working for The Skeptical Inquirer and the online magazine Live Science, greatly minimizes the amount of rain preceding the event and the speed at which wet clothes dried. Radford is correct to debunk fake miracles and false paranormal events, but like a lot of skeptics, he seems more interested in defending his agenda than seeking the truth. His biased discourse on Fatima, without concrete clues or careful consideration of the pictures and the testimonials, lead Dr. Stacy Transancos (2013) to seriously question the scientific relevance of Radford ad hoc hypotheses, set up well after the facts (absence of previous heavy rain, collective hysteria, retinal phosphenes, small crowd, etc.). The weather he imagines is at odds with the pictures and in opposition to the official weather reports.

In fact, many of those present were not only believers, but also catholic unbelievers, and like Radford, skeptics, agnostics, or atheists, who expected not to see miracles, and who would have been very happy to invalidate these religious accounts, if nothing happened. Carlos Mendes, Ferreira Borges, and 
Antonio Luis Vieira were incredulous Catholics; we found also witnesses among skeptics like Joao Machado, Antonio de Bastos, mayor of Santarem, and the engineer Mario Godinho who wrote after: "I could see the sun more easily than one can see the full moon ... as I never saw it again" (Barthas 1969, 349, 351-361; Haffert 2006, 55-61). But it is remarkable that the most convincing sources and photos came from secular sources. This withdrawal of Catholics is explained by the marked anticlerical climate in Portugal, and the violent media polemics around religious subjects. The main source of data on October 13 comes from the turnaround of the renowned secular journalist Avelino de Almeida (1873-1932). On the morning of Saturday, October 13, his newspaper $O$ Seculo published his skeptical and somewhat mocking article, predicting a total and shameful fiasco for the believers. But on the same day, de Almeida attended Fatima's "miracle of the sun", as he put it, and published against all odds, a particularly favorable article on Monday 15.

At first, the Catholic press remained in a wait-and-see attitude, fearing a coup against the Church. Nevertheless, the Catholic Newspaper A Ordem published an article on the $16^{\text {th }}$, by the jurist politician Pinto Coelho under the nickname A. de F., who posited the event could have been purely natural, such as an eye condition. Pinto Coelho invited Catholics to be prudent, rational, and subject to the Hierarchy. To my knowledge, he is the only eyewitness to have officially supported this hypothesis, recently taken up by Meessen (2006), but he was widely criticized by many other witnesses (Reis 2001, 259-270). In particular, Gonçalo Garrett began to debate against Pinto Coelho. Both were faithful Catholics willing to defend their faith but in opposite ways. Several ecclesiastics, not present at Fatima, supported Pinto Coelho's thesis. It became so controversial that many stopped subscribing to A Ordem, forcing it to reconsider its position (Brochado 1955, 165; Reis 2001, 265). Reis (2001, 266-269) describes Pinto Coelho as "an enlightened, militant and politicized" Catholic who feared Fatima events becoming "the clichés of obscurantist superstition”, "eventually providing a powerful weapon against the Church". Garrett was opposed to catholic political militancy and closer to the devotional approach and Christian life, as "means to achieve 
in a subordinate way political ends favorable to the Church" (see Barthas 1957, 148-150; Brochado 1955, 164-166).

Anyhow, the Catholic press had not taken any pictures, and their controverted retinal hypothesis did not convince the secular press either, which began its own debate 3 . Astronomer Frederico Oom from Lisbon Observatory, presented his "mass suggestion" hypothesis in O Seculo, contradicting de Almeida. So, de Almeida published a more detailed article on October 29 in the weekly Ilustraçao Portuguesa, with a series of photographs in support, those we analyze here. These photos were taken by Judah Bento Ruah, an engineer from a Jewish family of free thinkers, who replaced his absent uncle, Joshua Benoliel, photographer at O Seculo (Pires 2016). It is remarkable that this young amateur was able to take an average of one photo per minute, despite the 1910s' heavy and slow technology ${ }^{4}$. Contrary to the claims of current skeptics (Radford 2013 and 2019), the photos show a fairly large number of people barefoot and soaked in sticky mud, in places still wet

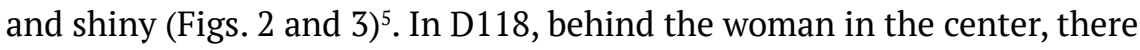
was a puddle and an empty area of people, probably too wet and muddy for the crowd to gather in. In these photos, almost all of them had umbrellas whose canvases often still appeared shiny and wet at the bottom of the folds (Fig. 3). Others had protected themselves with shawls, hats, or raincoats.

3 The Catholic debate predates October 13 and had been fueled since May 1917, by the ridicule of credulous Catholics towards Fatima, by the vigorous skeptical press. It is significant that the anticlerical newspaper $O$ Mundo, which had been unleashed in August against the 'farce' of Fatima, ceased publication the next day, 14 to 19 October 1917, following a 'staff strike', a staff that even founded another newspaper, A Manha. The secular debate began after October 13, partly launched against de Almeida and other converts (Barthas 1969: 169-175). See also testimonies and pictures at https://observador.pt/especiais/fatima-13-testemunhos-de-quem-esteve-no-dia-do-milagre-do-sol/.

4 The press camera was cumbersome, with a tripod, vertical adjustment system, dark cape to handle the sensitive glass plates, etc. It took skill and speed to choose a place, mount and focus the camera, calibrate and adjust the viewing angles, calculate exposure time, place and remove the plate in the dark, take the picture, etc., all in one minute! We can guess Ruah's haste in the partially veiled D116 (probably due to a handling error) and in the close shooting places (see the same people in D113 and D116; two passers-by in D116 are the kneeled women in D115).

5 Especially in D113, D115, D116. In D115, we can see lumps of wet mud stuck to the shoes of the kneeled woman in the center (see also Fig. 2). 


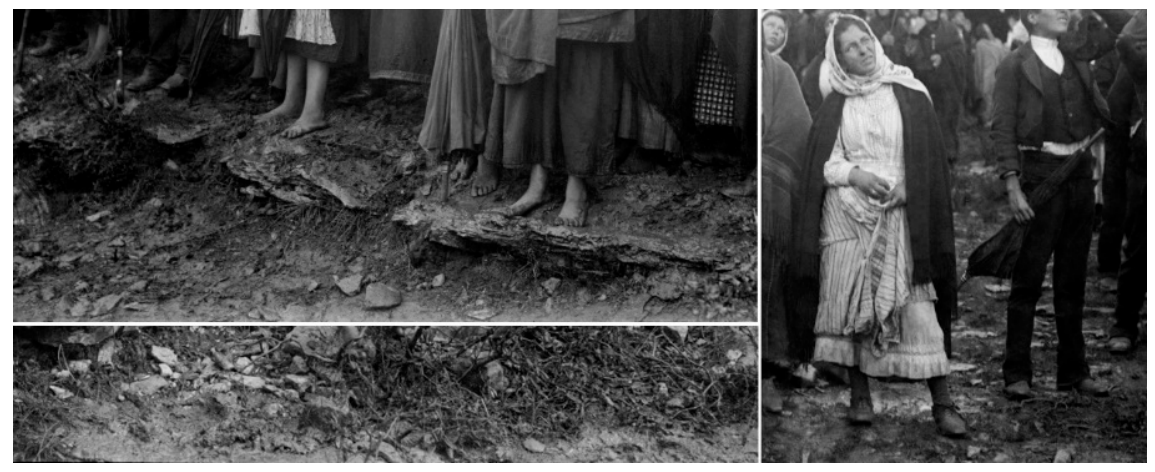

Figure 2. Barefoot, mud bathing stones and puddles (D113, D115, D118 details)

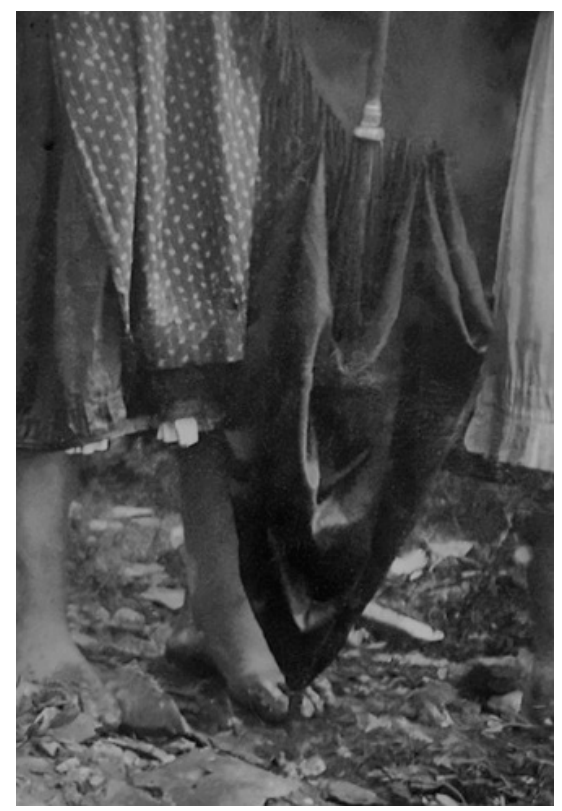

Figure 3. Reflections of dampness on the toes and lower folded parts of umbrella's canopy (D115 detail)

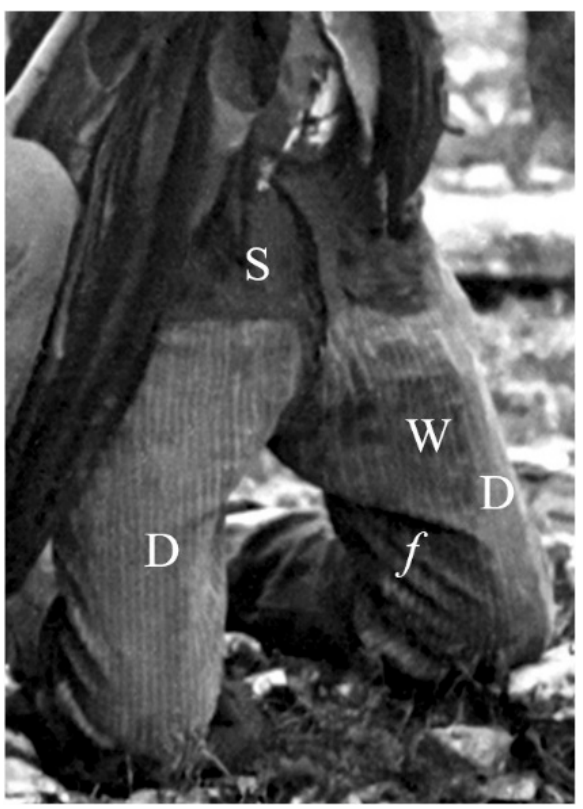

Figure 4. Pants areas. S: soaked, W: wet; D: dry, if exposed to $L S a$ (also $f$ : upper folds) (D115 detail) 
However, the most demonstrative case against Oom and Radford's ad hoc hypotheses is that of the young man (Fig. 4) in D115, who has kept his kneeled stance for a few minutes at most. The five inches of the upper part of his pants are soaked (explainable by his jacket's recent undoing, probably because of the heat radiated by $L S a$ ), while the areas exposed to $L S a$ for a few moments are dry. Besides, the inner part of the right buttock, less exposed, is still half wet, except for the few folds lately exposed to $L S a$. The strong contrast between the wet and the dry areas invalidates the unfounded assertions of the absence of substantial rain closely preceding the event. This also confirms the eyewitness accounts of fast evaporation, in October, by a heating source. The sharp infrared (IR) shadows printed by LSa on the wet and dry pants patterns, contrast with the barely discernible luminous shadows on the pictures, as we will see. Another IR shadow pattern appears on the raincoat covering the girl's head on D115 (Fig. 5), whose gaze stance toward the camera lasted a few seconds to about one minute, the time for Ruah to arrange and take the photo. For clothes to dry so quickly, one needs a blazing sun and a sustained wind. But an intense sun would be blinding and casting perfect shadows, and the wind alone (unnoticeable in D115) could not explain the dry folds on the wet buttock. Many witnesses at the Cova, spread over an estimated area greater than 4.5 hectares, reported an unusual fast drying of their clothes and a momentary strong wind (Barthas 1969, 358, 361; Haffert 2006, 11, 33, 37-45, 53-69, 89-91, 102 (witnesses map); Chalupsky 2017).

The hot and sharp LSa excludes false suns (parhelia or "sundogs") and other blurry atmospheric phenomena studied since the $17^{\text {th }}$ century (Tape, $1994,95-100 ; 2006,20-31)^{6}$. In 1917, no eyewitness and no meteorologist identified the phenomenon with parhelia, an ad hoc "explanation" that appeared years after the facts. Besides, against the analysis of Bowman and

6 See the works of René Descartes (1596-1650) in his treatise on Meteorology, of Christiaan Huygens (1629-1695) in his Halos and Parhelia, and of Father Edme Mariotte (1620-1684) in his Traité de la Nature des Couleurs. The analysis of these halos helped the prodigious development of mathematics in the 17th century, particularly with Huygens and his friends, Newton and Leibniz. Mariotte popularized them in France. 

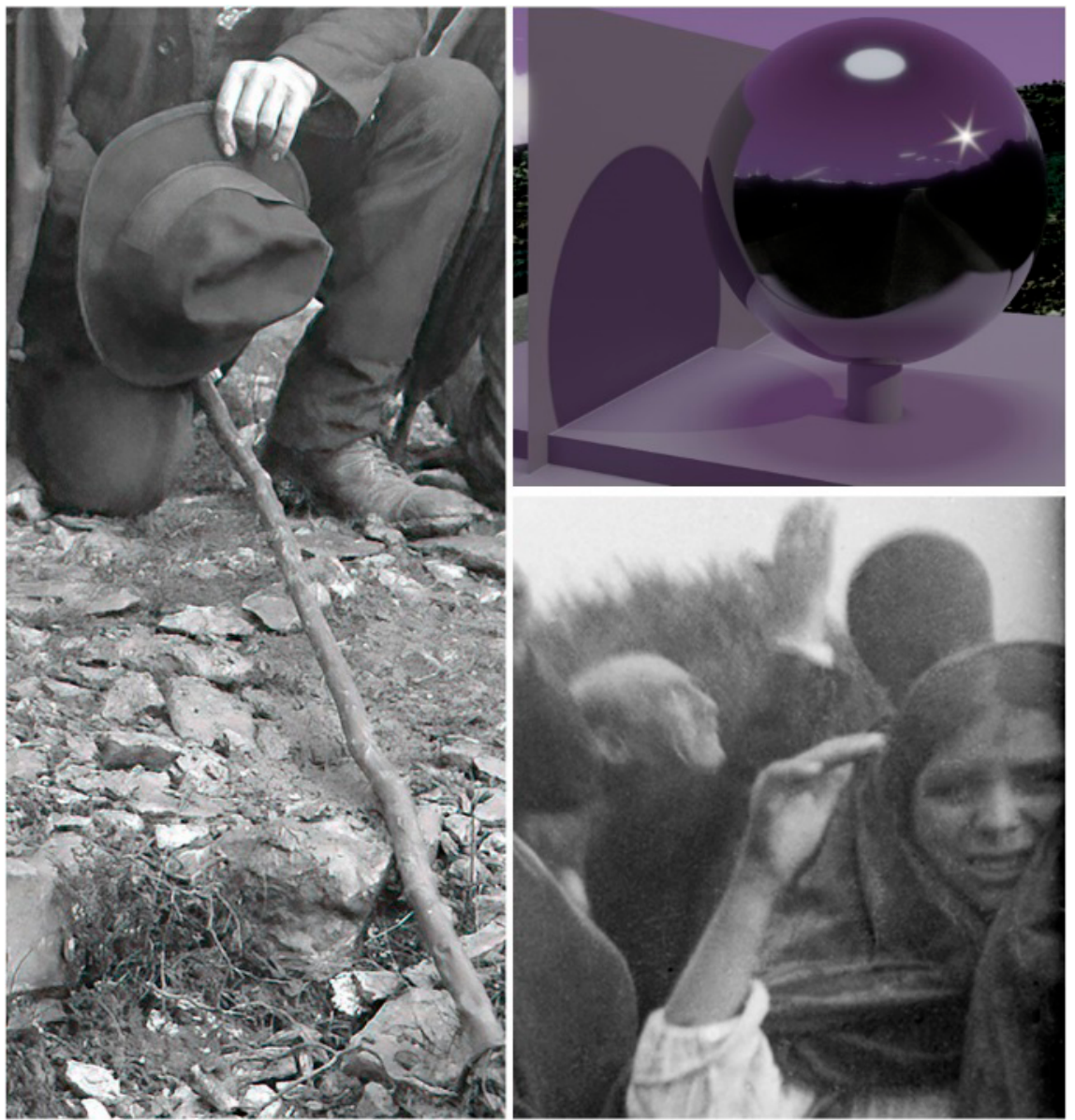

Figure 5. Ghost shadows. The staff's shadow fades with distance to the ground, but stands out on the pants where the hat hides $L S b$. The soft shadow projections on the hat's crease and brim, of its crown and the ear finger, show LSa's direction (D115 detail). Right above: Mirror-Ball Light-Probe Blender ${ }^{\circledR}$ simulation, with reflections of a starlike $L S a\left(30^{\circ}\right.$ height), a cloud disc $L S b$ ( $90^{\circ}$ height) and amethyst colored atmosphere. See shadows' visibility and sharpness differences on lying and sloping surfaces and under the sphere. Right down: Dark shadows on the eyes and upper cheek of the girl, and of her nose, eye and nasolabial fold on the upright surface of the raincoat covering her head. Those shadows are contrasted by the IR drying process, increasing raincoat's exposed areas reflectance. 
Nickel (1993, 177-178), sundogs are weak at high sun elevations, fainting above $40^{\circ}$ (Cowley 2020; Können 1985, 64, 65; see Garrett, note 1). The sun's height reached $42.72^{\circ}$ at the Cova ${ }^{7}$. Moreover, parhelia exhibit not one, but three visible "suns": the strong solar disc flanked by its two blurry prismatic "sundogs" at $22^{\circ}$ on either side and about the same elevation ${ }^{8}$.

Several meteorologists searched for other explanations. Wirowski and Szczerba (2019) present rare solar vibrations. But they do not explain the changes in color, fast rotation, sharpness, the non-glazing sun at noon in a clear sky, and the viewing toward Fatima from distant positions (see below). Campbell (1989, 333-338) proposed a cloud of fine dust for the pale white sun, moving from west to east ${ }^{9}$. Quoting two pictures from Aden and Marjorie Meinel (1983) taken in China by Peter Franken in 1978, he asserts that this dusty cloud would veil, tint, and even “swirl” the solar disc. Meinels' book (1983, 82-85, 98) cites the Mie light scattering effect, discovered in 1908 when the air is laden with dust or smoke from industries, volcanoes, or Loess storms. The two pictures (plates 8-5 and 8-6 on page 98) show a blue dull sun, veiled by a dust mist whose color goes from blue near the sun to red far away from it, very different from the clear sky of Fatima (Haffert 2006, 96). Moreover, no Chinese or European called for a "miracle”, observing such phenomena. But to our knowledge, contrary to Campbell's assertion, later taken up by various without confirmation, Meinels' book nowhere mentions any meteorological impression of a "rotating" sun. Besides, the only possible explanation Campbell sees for Fatima, are clouds of volcanic smoke. These clouds travel thousands of kilometers for days, even months,

7 Parhelia are mostly seen near the polar regions as two blurred solar images: https://jari. pic.fi/kuvat/Atmospheric+phenomena+and+sky/Atmospheric+halos/. See Halo simulator (C Cowley \& Schroeder) downloadable at https://www.atoptics.co.uk/halo/downld.htm. The solar noon at the Cova occurred at $13 \mathrm{~h} 21 \mathrm{~m} 04 \mathrm{~s}$ with a sun height of $42.72^{\circ}$, higher than $42^{\circ}$ from $12 \mathrm{~h} 45$ to $13 \mathrm{~h} 56$ (online calculator: https://www.suncalc.org/\#/39.6317,$8.6729,16 / 1917.10 .13 / 13: 21 / 1 / 3)$.

8 Nickel mentioned azimuth and elevation variation, but corrected it in later editions, restricting it to azimuth.

9 In a brief note after Campbell's article (p. 338), the editor of the Journal of Meteorology, Terence Meaden, presented another possible "explanation", a show of a plasma vortex, a dubious theory he used to explain the controverted "crop circle" formations. 
and give much more extensive and persistent atmospheric effects than those of October 13. Campbell is unable to point out a volcano to produce this effect locally in Portugal. The physicist Fr. Stanley Jaki $(1999 ; 2000)$ conjectured an "atmospheric lens" at noon, but it would be a brand-new observation of an unparalleled rarity in the history of meteorology, which came just in time to spare the three children the shame of failure. Wirowski, Jaki, and Campbell recognize the tiny probability of their hypotheses and the remarkable coincidence with the predicted moment in Fatima ${ }^{10}$.

What could have motivated these children aged 7 to 10 to launch such a risky "bet", months in advance? But what a masterstroke, because they won their bet, if it was a bet, despite the weather forecast! The official meteorological data of October 13, 1917, confirms the photographic and witness analysis. The "European Centre for Medium-Range Weather Forecasts" (ECMWF) has recently reproduced weather maps from the end of the 19th century to the present day, based on the CERA-20C European meteorological dataset from civil and military observatories ${ }^{11}$. This database indicates that on October 13,1917, at noon in Portugal, a large rainy area extended from eastern North America (the central part was still dark) to Russia. Those data alone explain that no European and North American observatory, including Lisbon and Coimbra, could observe the sun during the short minutes of the event at a localized clearing near Fatima. While the weather had been better on the $11^{\text {th }}$, European news indicates that on the $12^{\text {th }}$ and $13^{\text {th }}$ of October, the whole of Europe, then in the middle of the war, was under a thick, rainy, tenacious, and in places stormy cloud layer. Newspapers reported heavy rains, sustained winds, despite brief clearings here and there ${ }^{12}$. On October 13, there were torrential rains in Valladolid,

10 Quickly evolving altocumulus lacunosus clouds, different from the 1917 event delicate clouds, may produce fast solar iridescence effects (see Cowley at http://atoptics.co.uk/ fza220.htm).

11 CERA-20C database is accessible on www.ecmwf.int, from which several weather maps are produced, as in https://www.wetterzentrale.de/reanalysis.php?jaar=1917\&maand=10\&dag=13\&uur=1200\&var=4\&map=1 \&model=era ; http://archives.infoclimat.net/ 20e/1917/10/13-rr-eu.png?v5.2r812.

12 Several newspaper archives can be checked online: A Capital (Portuguese Republican Newspaper); La Vanguardia; La Correspondencia militar, La Época, El Liberal, Spanish news- 
Spain, and at the battlefront in France. The weather discouraged planes from taking off, and several planes were reported missing, probably due to the storm ${ }^{13}$. In Portugal, the weather was gloomy, and the temperature in Fatima rose to $15^{\circ} \mathrm{C}$ around noon, with a medium-strength wind. This constant westerly wind for several days undermines Paul Simons (2005) hypothesis of Sahara sand dust solar effects, never observed in Portugal before or after. It rained intermittently, at times heavily, totaling 1 to $2 \mathrm{~cm}$ of water in 24 hours. Despite this, the Cova da Iria experienced a continuous influx of people, with no indication that this dreary weather would improve by the time indicated by the children.

According to many witnesses, at 1:00 pm (local time) the rain stopped, the sky cleared fairly quickly, and a strangely distinct "sun" emerged rather pale, not dazzling, in a blue sky delicately veiled by some cirrus clouds. However, we have no direct photograph of the "sun". This will be a surprise for those who know little about press photography a century ago. There are several reasons for this:

$1^{\circ}$ there were few photographers when cameras and light-sensitive plates were bulky and difficult to use (see note 4 above);

$2^{\circ}$ given the bad weather, nobody thought they had to photograph the sun, which required additional special equipment (van den Aardweg 1988, 25-26). Moreover, many press photographers did not use filters (Kinkaid 1936,177) and any extra manipulation could slow down the taking of pictures. Meteo- or astrophotographers would have taken sophisticated equipment when scientifically notified of the location, time, and type of an aerial event. Radford's (2019) assertion that some people prepared sun filters or even sunglasses, is not supported by any photograph and certified testimony.

papers archived at http://hemerotecadigital.bne.es; L'Écho de Paris, Le Figaro, Le Temps, French newspapers archived at http://gallica.bnf.fr; etc. See also the New York Times forecast (October 12, 1917 pages 1 and 19) for October 12 evening and October 13, of a "strong anticyclonic depression of considerable intensity" accompanied by rain and a "sharp drop in temperature" throughout the Northeastern United States.

13 Cf. Communiqué Britannique in L'Écho de Paris, Oct. 14, 1917, p. 1.

ScientiaetFides 9(1)/2021 
$3^{\circ}$ few photographers ventured to take pictures in this dreary weather and remote place, risking damage to their cameras and to miss pictures;

$4^{\circ}$ an alleged photograph of the sun without a recognizable crowd is far less convincing because it can easily be forged. The presence in the photos of thousands of witnesses, painlessly staring at a celestial light, many of them identifiable and accessible to journalists or investigators for years, is more convincing and harder to falsify, than a fake photo using a lamp (see Nickel 1993, 198).

In fact, two fake pictures of the "solar miracle" still circulate today with no distinct crowd and were even published by the Osservatore Romano on November 17, 1951. Skeptics were quick to point the error out. The official magazine of the Sanctuary, Voz da Fátima, denied their authenticity ${ }^{14}$.

\section{Unusual shadows of two soft light sources.}

Some websites and magazines circulate fake pictures of the crowd taken in the 1920s, displaying sharp sun shadows unlike the authentic Ruah's pictures ${ }^{15}$. Curiously, most of the shadows of Ruah's pictures are faint, making it difficult to accurately locate the "sun". A detailed analysis of the soft reflections, shadows, and shades, unveils many characteristics of the

14 Voz da Fátima, June, 13, 1952, p. 2; the pictures were taken at sunset on May 13, 1921, $16 \mathrm{~km}$ from Torres Novas, near the chapel of Lourdes, and were delivered by the bishopric of Leiria. Cf. Osservatore Romano, Nov. 17, 1951; Life Magazine, Dec. 3, 1951, p. 45 and May 12, 1952, p. 20; Brian Dunning, Illuminating the Fatima Miracle of the Sun, Skeptoid Podcast \#110, July 22, 2008, script available at https://skeptoid.com/episodes/4110; The Miracle of Fatima: Photographic Proof from the Vatican and LIFE magazine? Dec. 9, 2013, on https:// www.blueblurrylines.com/2013/12/the-miracle-of-fatima-photographic.html.; van den Aardweg $(1988,25)$ estimates the whole story may be an anticlerical trap.

15 The apparitions were marked by a rustic arch, criminally destroyed on October 22, 1917. A chapel replaced it in 1919, criminally blown up on March 6,1922. The replacing constructions seen in the pictures falsely dated on October 13, 1917, were built years later. From these photos, some falsely count the crowd of 1917. Carlos Manuel Goulão, a grandson of the photographer, uploaded the photos, dating them from the 1920s https:/www. flickr.com/photos/cgoulao/395241158/in/photostream/ https://www.flickr.com/photos/ cgoulao/373617846/in/photostream/. See http://www.paranormal-encyclopedie.com/ wiki/Articles/Miracle_du_Soleil; http://seasonsofgrace.net/so-that-all-may-believe-themiracle-of-the-sun-2/ (accessed Nov. 12, 2020). 
sky's brightness map. Spectators' eyes point toward $L S a$, which stays out of the shot's frame ${ }^{16}$. However, D115 shadows reveal overhead a second source $L S b$, about as bright and fairly diffuse as seen on hazy casted shadows. It was probably a bright isolated cloud able to muffle $L S a$ 's casted shadows, turned imperceptible on lying areas, but discernable on sloping surfaces or under some object, where $L S b$ 's effect weakened (Fig. 5, 6 and also Fig. 1 and 2).
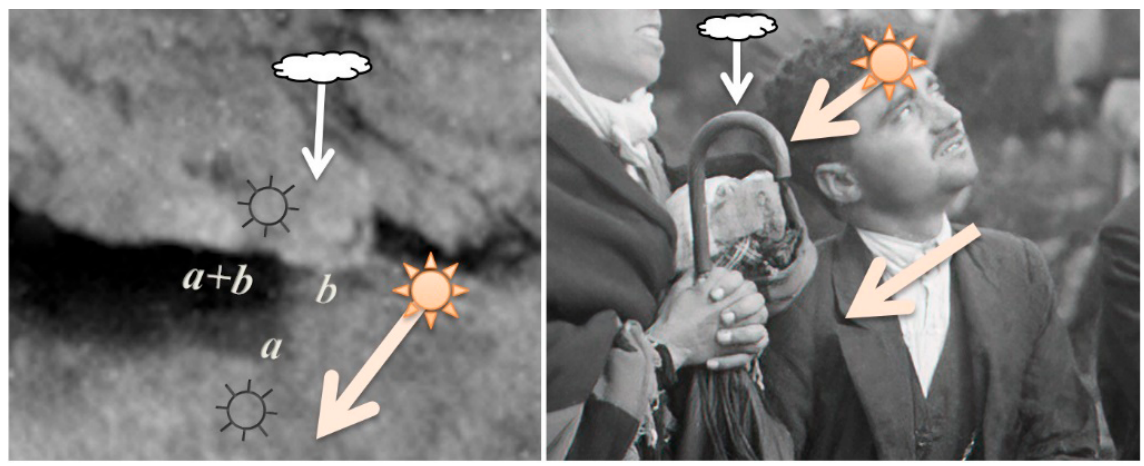

Figure 6. D115 details. Left: double shadow, $a$ (from $L S a$ ) and $b$ (from $L S b$ ) of a flat stone on a sloped surface, ( and $L S b$ rays). The deep black of $a+b$ bares a low ambient light. Right: $L S a$ and $L S b$ specular reflections on umbrella's handle. Note also the lapels shadow on the upright jacket front, and the reflections on the cornea of the eyes.

The luminance of a typically lit cloud (3 to $10 \mathrm{kcd} / \mathrm{m}^{2}$ ) with a solid angle of hundreds of square degrees, appears much darker than the sun, and yet brighter than the moon. Thus, contrary to van den Aardweg $(1988,25)$ or Haffert (2006, 10, 42), and consistent with eyewitnesses, the ambient light must have been low, adding a mysterious impression to the phenomenon (Barthas 1969, 345-347, 358, 361-362; Haffert 2006, 59, 62, 93). Ruah seems to have compensated for this low light by a longer exposure (see the blurred moving left foot of a passer-by in D116) and a wider aperture, giving a background blurred effect by reducing the depth of field to a few

16 Some people watched the horizon, the crowd, or the photographer, an unusual attraction for people not accustomed to the practice of photography. 
meters (Fig. 7; cf. Kinkaid 1936, 99-101). Besides, by 1917, a bluish color temperature (see below the violet colored environment) boosted the black and white picture brightness, a well-known problem for realistic sky contrast and outside picture shades (Peres 2013, 47, 61, 74, 109-110, 333, 723) ${ }^{17}$.

In October 1917, Jose Maria Garrett completed two significant experiments. During the event, he stared at the "sun" for a few minutes, without lasting retinal phosphenes or photopsia (typical sunspots ${ }^{18}$ that moved with the eye), unlike some days later, after staring a few seconds at the sun (Coelho and dos Santos 2013, 149-152; Gomes 2017; Barthas 1969, 345-347; we highlight keywords):

It was a wonder that all this time it was possible for us to look at the sun, a blaze of light and burning heat, without any pain to the eyes or blinding of the retina... It was rotating upon itself with exceedingly great speed... I noticed that everything around me darkened. I looked at what was near and cast my eyes away towards the horizon. Everything had the amethyst color: the sky, the air, everything. A purple oak nearby was casting a thick shadow on the ground. Fearing a retinal impairment - an unlikely hypothesis, because then I would not have seen everything in purple - I turned about, closed my eyes, cupping my hands over them to cut off all light. With my back turned, I opened my eyes and realized that the landscape and the air retained the same purple color ... the atmosphere, though purple, remained transparent to the edge of the horizon, which was clearly visible and distinguishable.

So, José Maria Garrett turned his back on the "sun" without any blinded sunspot following his gaze. Yet, a few days later, a short look at the sun did not produce a purple "uniform color as if topaz had volatilized into the air, but spots and specks that moved with the movement of the gaze". These localized spots were very different from his view in Fatima. This testimony

17 Photographers could also adjust the exposure during development to adapt the brightness and contrast of the final image, as in digital processing today. This explains Haffert's false impression of hard sunshine, contradicting reported testimonies. Reduced luminosity is also reported by witnesses during earlier Fatima appearances, especially on September 13 (Barthas 1969, 148, 358).

18 These spots are due to bleaching of the cone and/or rod cells. Their yellowish-looking stain blinds the affected retinal area for several seconds to minutes depending on the intensity and duration of solar fixation. They remain with closed eyes. 


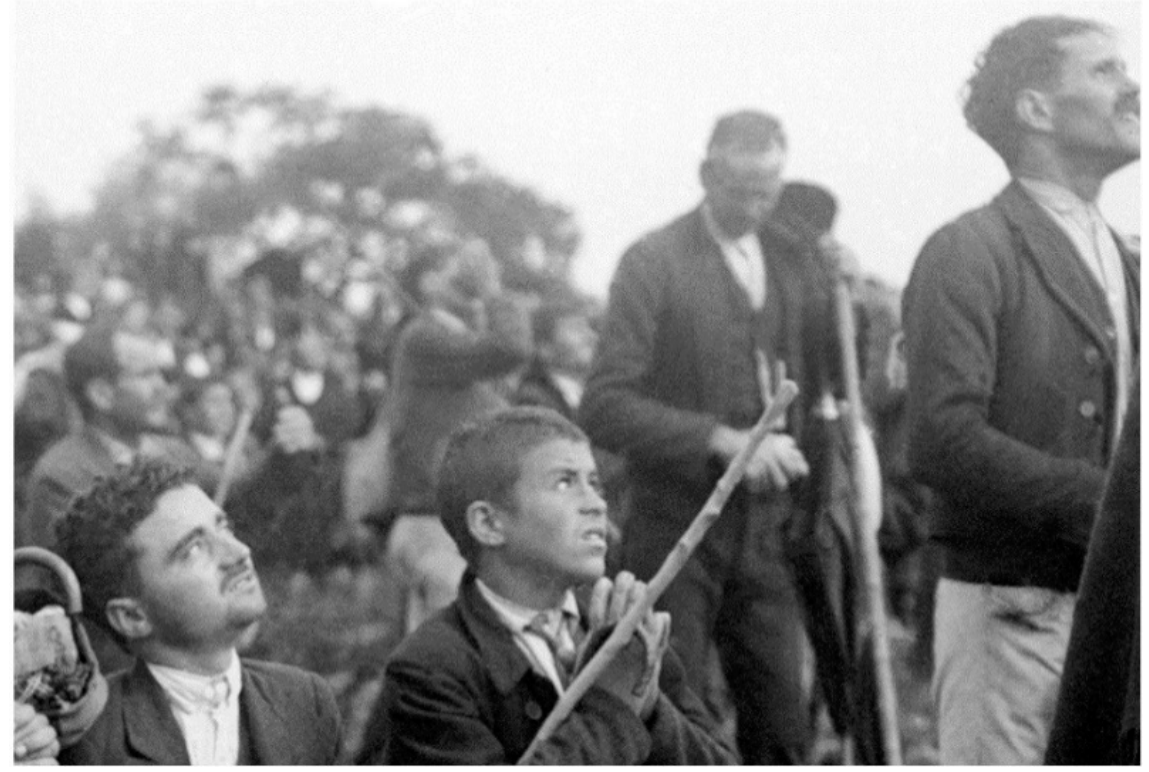

Figure 7. Large negative plates reduce the depth of field, which seems to be yet smaller on picture D115, probably due to a wide aperture compensating for low light.

formally contradicts the hypothesis of solar phosphenes put forward by Pinto Coelho (see above), Meessen (2006, 204-205), and others.

How could common solar phosphenes, observed for several minutes without verified retinopathies, have been confused with a "solar miracle" by thousands of people, including scientists? A solar rotating effect was never seen before, even in other claimed "sun miracles" as at Tilly-sur-Seulles in 1901. Gonçalo Garrett witnessed the Fatima firework "sun”, but added that, until October 1917, "no one saw solar sparkling rotations, and now all sorts of people see them many times and days. Much will be imagination" (Coelho and dos Santos 2013, 147). Because of observer cognitive and desire bias, a psychological illusion of gyrating suns in highly motivated skeptics, scientists, or believers (the first to trivialize the illusion, the last to experience a miracle), seems more probable after Fatima accounts, than Oom's supposed spontaneous mass suggestion at Fatima. 
Besides, according to Pinto Coelho and Meessen, a large crowd gazing several minutes at a dazzling object, will experience strong retinal persistence with multicolored impressions and even "rotatory movements". But statistically, this should have caused various lasting scotomas and lesions. In fact, during unprotected observations of the sun or solar eclipses for periods of several tens of seconds, long-lasting solar retinopathies are frequent, sometimes month-lasting and permanent with serious reading disability (Weng et al. 2020; Abdellah et al. 2019; Källmark and Ygge 2005) ${ }^{19}$. The same arguments apply to other reported testimonies (Wirowski 2012; Wirowski and Szczerba, 2019). Such retinopathies were also reported after some false prophecies abusing people's trust (Sheemar et al. 2017; Thorton 2009; Källmark and Ygge 2005; Mwanza et al. 2000; Hope-Ross, Travers and Mooney 1988; Nickel 1993, 196-200) ${ }^{20}$.

Not a single witness or doctor reported any solar retinopathies due to the Fatima event, despite the photos not showing any protective sun filters or glasses. In contrast, most witnesses were amazed that the distinct "sun" at the Cova, could be fixed without effort or danger, except for two or three moments when one had to look away or protect oneself with the hand ${ }^{21}$.

Moreover, Meessen and Pinto Coelho do not give a complete report: they do not say how long it took to regain normal vision after their experiments, nor whether they felt any discomfort during or after them ${ }^{22}$. It is also un-

19 Källmark and Ygge point out that after the total eclipse of August 11, 1999, in Stockholm (partial eclipse between 9:40 am and 12:00 pm GMT, with maximum 80\% of the sun obscured), 15 patients between 17 and 51 years old, went to the hospital for solar retinopathies in one eye, none of them having looked directly at the sun with both eyes. Estimated times of fixation of the partially obscured sun varied between 20 and 300 seconds. Even after symptomatic recovery many patients still had scotomas after one year.

20 Cf. https://apnews.com/article/6c2200ff14030f3e618066fa27745bda accessed Nov. 13, 2020. See also above the Campbell hypothesis mentioning Franken's observations.

${ }^{21}$ It could be so in D118. However, the position of the hands and the opening of the fingers on the pictures, seems to be due to either concentrated attention, a simple reflex, or an attempt to improve the contrast to better see the details in the "solar disc", like someone scrutinizing the horizon, hiding the zenithal light with his hand.

22 To my knowledge, rotational and spiraling illusions of retinal bleached (saturated) sunspots are scientifically undocumented. Most motion illusions are non-dazzling. Fast spinning sun "explanations" appear oddly made up to fit the testimonies. Meessen (2006, 205-206) admits he could not observe any solar disc rotation, stopping his experiment 
realistic to assume that distant people, unaware of what was happening in Fatima, could willfully persist in gazing the "normal" sun conjectured by Pinto Coelho and Meessen, until they get strange visions and effects, risking eye damage. For us, the explanation is more coherent: the pictures show, as Jose Maria Garrett confirmed, ruling out solar phosphenes, that the "sun" was far from being as bright and hurtful as some assume.

\section{Witnesses tens of miles away}

A common fault of most critics of the Fatima miracle is to ignore or depreciate the testimony of distant people who could not share the expectation or the emotions of the crowd at the Cova (Barthas 1957, 136-138). We analyzed testimonies from four locations more than $10 \mathrm{~km}$ away (see Fig. 8), where people saw the same event in the Fatima direction over an area greater than $1000 \mathrm{~km}^{2}$. The watching directions do not point toward the sun at this time of day, the southern azimuth close to $180^{\circ}$. Those data, taken up by various witnesses, have gone unnoticed or ignored. Meessen $(2006,203)$ seems to ignore this directional effect, as if the various distant perspectives were identical, with the unhidden sun as the only possible source of the eye and cerebral illusions he defends ${ }^{23}$.

prudently. But many have been treated for having pushed the experiment further, during solar eclipses for example, and did not report any sun spinning illusion. Fast scintillating scotoma is generally due to a visual or ocular migraine of cerebral origin, evolving slowly for about 20 minutes and moving with the gaze. This brightness-independent condition is not rotational and impossible to affect a heterogeneous crowd. Autokinetic illusions are punctual, not rotational, lacking reference frames, causing easily spatial disorientation. Spinning Wheel Pattern gives a slow rotational illusion due to wheels spiral patterns, affecting peripheral vision. Induced vertigo, dizziness, Coriolis illusion, induced self-rotation illusion, rotational aftereffect, or spiral MAE, are brain reactions to a prolonged observation of large spinning objects. They extend to the whole field of vision (Archimedes or Plateau spiral illusions, etc.; see Blom 2010, 8, 36; Wade and Heller 2003, 381-384; de Montmollin 1956, 462). These motion-induced vections cannot be limited to the tiny sun disc $\left(0.52^{\circ}\right)$, and are very different from the Fatima edge spinning sun with a linear passing-by of delicate clouds.

23 The almost full sky clearing near Fatima does not mean a same kind of clearing far away. Meessen (2006, 200-203, 207, 213) also rejects UFOs hypothesis as it requires large objects and tremendous amounts of energy. 


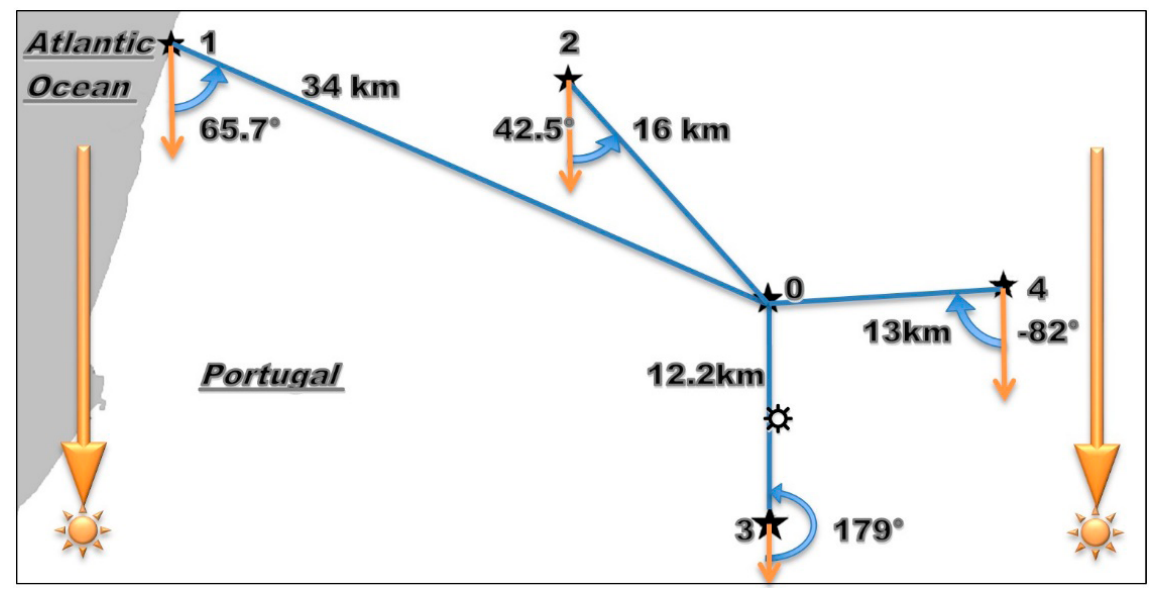

Figure 8. Distant witness locations and viewing directions relative to the sun, at 13:21, October 13, 1917. 0 Cova da Iria; 1 Family of Afonso Vieira (São Pedro de Moel); 2 Ghuilhermina da Silva + workers (Leiria); 3 Albano Barros (Minde); 4 Lourenço Brothers + villagers (Alburitel); ; estimated location of the event. Cf. van den Aardweg [1989, 27], Haffert [2006, 39-42], Campbell [1989, 335], Barthas [1957, 136-138].

The first case is that of the family of Afonso Lopes Vieira, a famous poet in Portugal. On October 13 at noon, he was on the veranda of his house by the sea in São Pedro de $\mathrm{Moel}^{24}, 34 \mathrm{~km}$ as the crow flies, from the Cova (Haffert 2006, 40). Suddenly, he was surprised to see a distant light show toward the mountains. He remembered that it was in the Fatima direction and connected it with the prediction he had forgotten. He called his wife and mother-in-law to come and see. But the Fatima direction makes an angle of $65.7^{\circ}$ to the east of the sun at noon.

The second case is that of Mrs. Ghuilhermina da Silva (Haffert 2006, 41-42) from Leiria, $16 \mathrm{~km}$ northwest of the Cova. Mrs. da Silva recounts that she had seen the crowd leave Leiria in large numbers heading toward Fatima. She was anxious to accompany them, but her skeptical husband prohibited her from going. Resigned, she found a place from where she could see the Fatima mountains to the east: "I was looking toward the

24 This house now holds a museum dedicated to Afonso Vieira. 
mountains at noon when suddenly I saw a great red flash in the sky. I called two men who were working for us" she said. But Mrs. da Silva added that the mountains between Leiria and the Cova hid part of the event from her. From her house, the elevation of these mountains above the horizon is a maximum of $2^{\circ}$ to $3^{\circ}{ }^{25}$. So, the event was to take place, from her point of view, at a relatively low altitude above the mountains ${ }^{26}$. Mrs. da Silva also reported the later eyewitness accounts of the descent of the "swirling sun" and the rapid drying of clothes.

The third testimony is that of Albano Barros (Haffert 2006, 40-41), then 12 years old, near Minde, $12 \mathrm{~km}$ south of the Cova. He was tending sheep in October 1917, when, "suddenly there, in the direction of Fatima, I saw the sun fall from the sky". However, from his location, the Fatima direction is due north, opposite to the midday sun. According to this testimony, the phenomenon could have unfolded vertically near Minde, or northwards near Fatima on the other side of the hill.

The fourth testimony comes from brothers Joaquim and Ignacio Lourenço (respectively 12 and 9 years old). These boys saw the event with pupils of their school, their teacher Delfina Pereira Lopes with her daughter Myriam, various teachers, and several inhabitants of Alburitel, $13 \mathrm{~km}$ east of the Cova. Joaquim and Ignacio were very impressed by this vision. Later, both became priests ${ }^{27}$. Their testimonies (Haffert 2006, 39-40; Barthas 1957, 136-137; Brochado 1948, 185) recount how, alarmed by cries in the street, they left the school and saw that the "sun seemed pale and did not hurt the eyes." "Looking like a ball of snow revolving on itself, it suddenly seemed to come down in a zigzag, menacing the earth."

The comparative analysis of these testimonies, shows that the event was probably located above the hills a few $\mathrm{km}$ south of the Cova da Iria. None of

25 Near Chainça, $10 \mathrm{~km}$ away, these hills exceed $400 \mathrm{~m}$ above sea level.

26 If Haffert's information (address: 20, Rua Nossa Señhora da Encarnação) is correct, these mountains are not visible from the ground floor because of the slope of the street and the hill of the sanctuary of Nossa Señhora da Encarnação. All the houses on this street going south-southeast, were contiguous, ending with the high bleachers of Leiria's Bullring. They had an east-northeast façade which allowed to look to Fatima from an upper floor, but not to the South, making it impossible for Mrs. da Silva to watch the noon sun.

27 Joaquim became rector of the Shrine of Fatima, and Ignacio a missionary in India. 
the remote witnesses mentioned the sensation of warmth felt at the Cova, perhaps due to the larger distance from the source, which appeared pale and spinning. At this hour, their view from distant different perspectives, pointed towards Fatima and not to the sun. From the Fatima scene, prof. Gonçalo Garrett spoke of circular edge spinning, not the whole sun disc (see note 1), different from the self-rotating snowball from Alburitel's view. Most of the witnesses called their vision to be the "sun" falling toward Fatima. But it could not have been $\mathrm{so}^{28}$.

However, these testimonies invalidate any attempt at "coherent" explanations made so far: meteorological, physiological and psychological phenomena, mass suggestions or "collective" hallucinations. Dutch psychologist van den Aardweg (1988, 22-30) believes that subjective and psychological explanations are insufficient and that the phenomenon in Fatima was real, objective, and produced measurable effects. Like Haffert (2006, 78-81), van den Aardweg adds that all naturalistic explanations to date do not account for all the observational details and credible testimonies (see also Campbell 1989, 335).

It is not a question, however, of giving up explaining the phenomenon, but of eliminating defective explanations. A coherent interpretation is not easy. As mentioned by van den Aardweg such an interpretation risks putting forward hazardous or partial hypotheses. According to our purpose here, we will refrain from giving new interpretations, limiting ourselves to providing elements of objective research. We have already cited some objective elements that have often been ignored, rejected or passed unnoticed in various explanations (heavy rain, clearing at the expected time, quick drying, weak luminosity, close to Fatima, etc.). But there remains one that seems never to have been analyzed so far. Can we compute the elevation of $L S a$ from the pictures? We will see that this poses an additional conundrum that seems appropriate to add to the Fatima case.

28 According to Lucia, Virgin Mary never named the sun but merely invited the children to follow her hands pointing to the light "suddenly visible" in the celestial azure. Lucia declared in good faith: "Look at the sun!" Many then spoke of the sun, but some witnesses said it was not (see Barthas 1969, 130, 361; Garrett in note 1). 

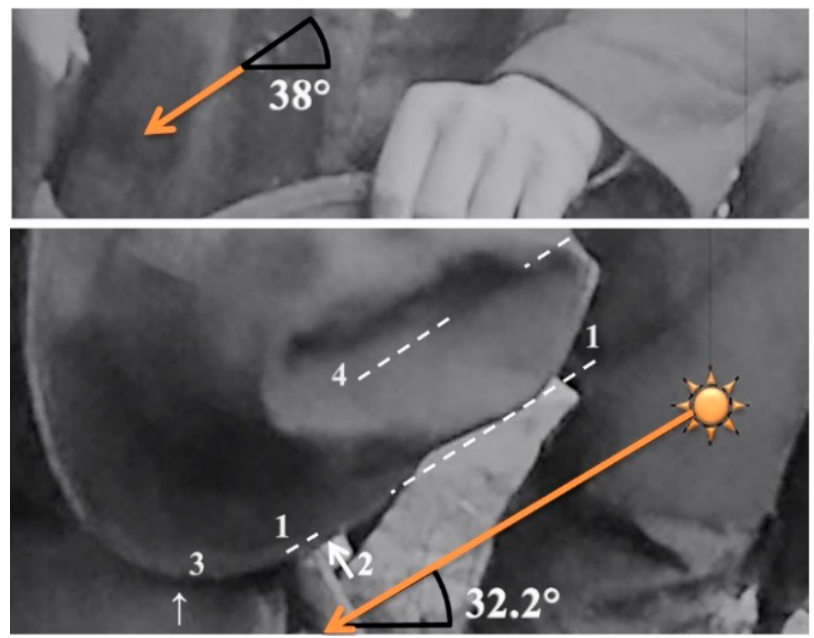

Figure 9. Perspective direction of shadows on D115 (denoise by Topaz ${ }^{\circledR}$; contrast by Blender $\left.{ }^{\circledR}\right)$. The projected direction of $L S a$ rays varies from $32.2^{\circ}$ to about $37.40^{\circ}$ (symmetrical reflections on a perpendicular knob). 1: tangent shadow of the crown on the brim of the hat. 2: dark grazing shadow on a back white object, of the brim in contact with the stick. 3: thin brim's shadow on the buttock, almost in contact with it. 4: shadow on crown's crease.

\section{4. $29^{\circ}$ "sun" height?}

The spectators viewing direction and the rays marking the faint light shadows converged to one source: $L S a$. We noted that sun's elevation at Fatima was higher than $42^{\circ}$ from $12 \mathrm{~h} 45$ to $13 \mathrm{~h} 56$. However, several testimonies and some photos suggest a lower value (Haffert 2006, 8, 87-93).

This impression is confirmed by analyzing the shadows in three estimation steps:

$1^{\circ}$ Estimation in the photographic frame of the vanishing point $\mathrm{VPa}$ of $L S a^{\prime}$ s parallel rays. It is far preferable to look for $L S a$ shadows almost undisturbed by $L S b$, on sloping surfaces or under some object. The further apart and the longer the shadows are, the greater the accuracy of $\mathrm{VPa}$ 's estimated position. In Figure 9, the delicate shadows of the hat's crown, its crease and dent, are noticeable on its near-vertical brim and under its crown. 


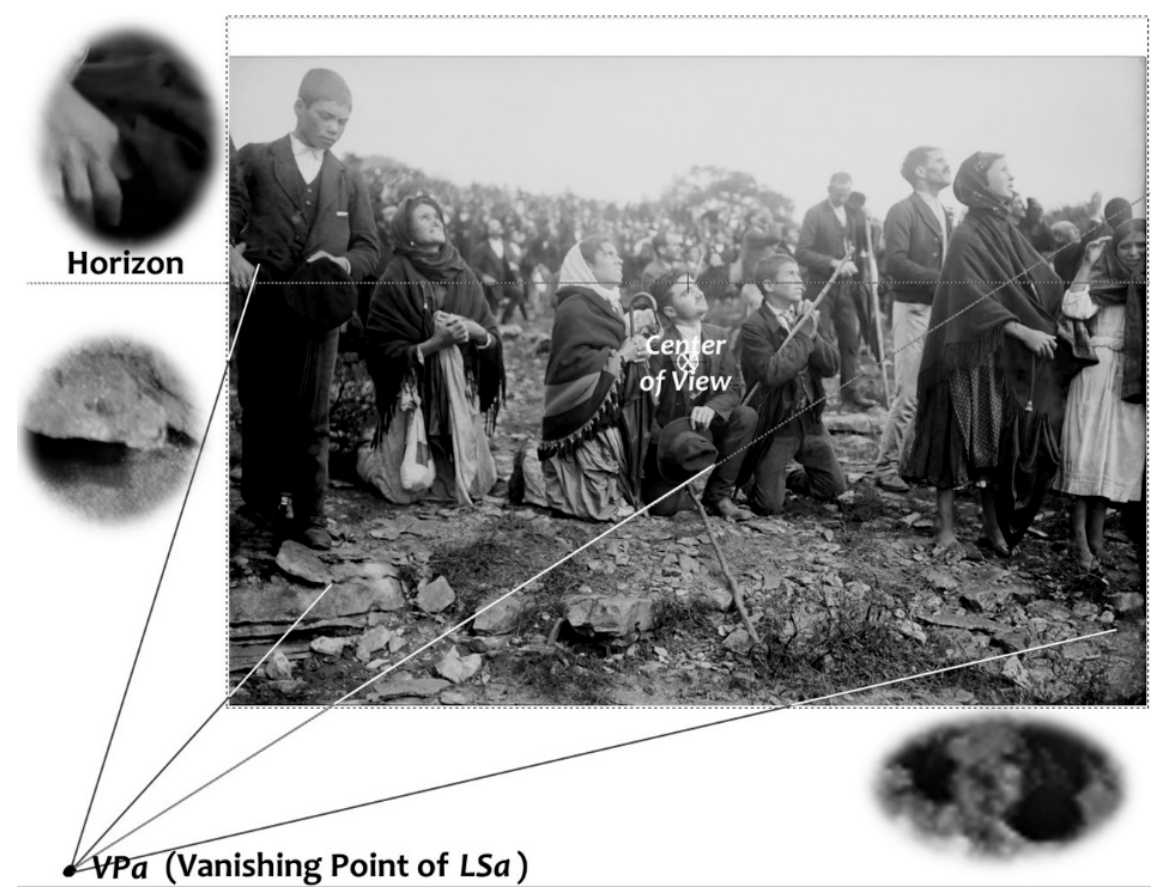

Figure 10. Estimation of the vanishing point $V P a$ of the light rays from $L S a$. $V P a$ corresponds to the camera's shadow position on the photographic plane. Besides the hat's shadows, we present three cases where LSb's lighting is weak (more shadows help refine the results). The camera points towards the center of view $C$, below the horizon line $\mathrm{H}$. This slightly tilted perspective renders vertical directions as somewhat convergent. $\mathrm{H}$ is estimated around the hips of standing people and from the expected height of the tripod+camera (about $1.5 \mathrm{~m}$ ) placed $50 \mathrm{~cm}$ down the slope, about $1 \mathrm{~m}$ above the people's ground (just over the umbrella in the center). $C$ is estimated from the size of the negative plate (probably $12 \times 9 \mathrm{~cm}$, continental standard in 1917).

These shadows give a precise enough direction of $V P a$ out of the picture ${ }^{29}$. Figures 9 and 10 show other shadows to guess $V P a$ 's position (see Fig. 6).

${ }^{29} V P a$ is the $L S a$ 's photographic location when $L S a$ is in front of the camera. $V P a$ is the image of the divergent source of rays from $L S a$. In D110 and D116 shot in front of $L S a$, the vanishing point is $L S a$ 's projection. VPa seems to fall in-frame on D113 and D114. When $L S a$ is behind the camera as in $\mathrm{D} 115, V P a$ is the convergent point of the rays, opposite to $L S a$. It corresponds to the camera's shadow position on the photographic plane. 


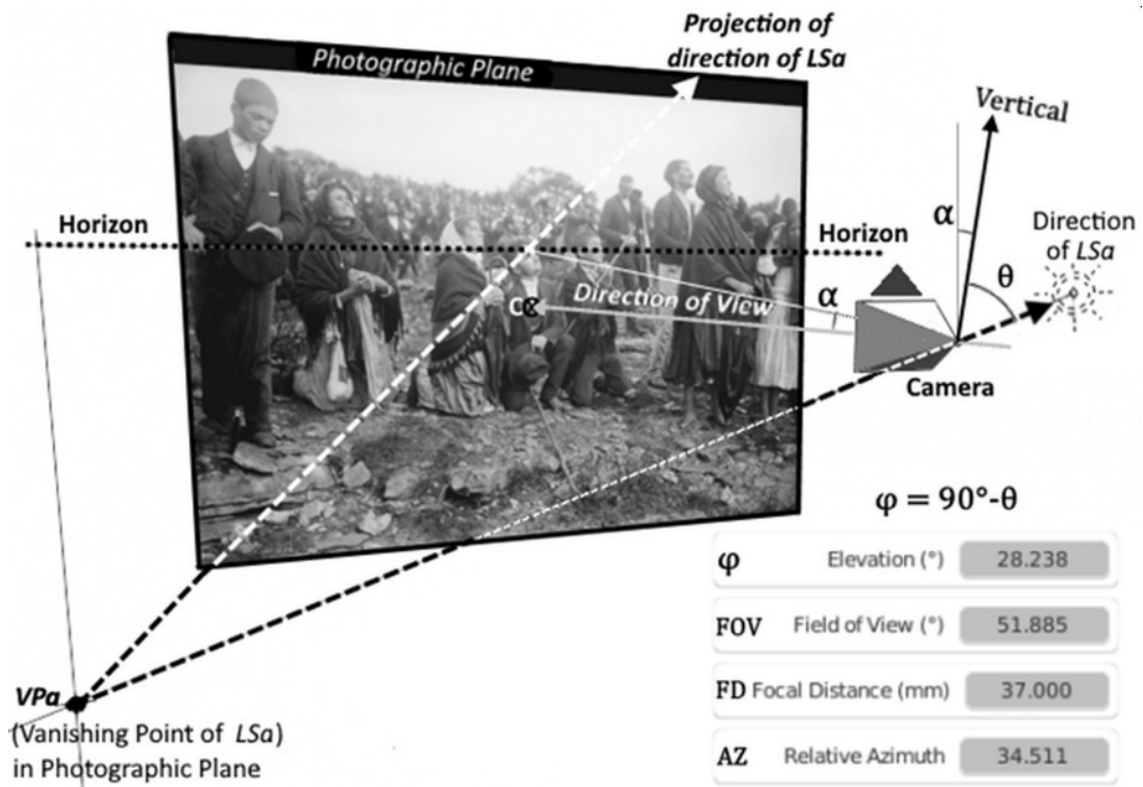

Figure 11. 3D vector [Camera - Vpa] gives the direction of $L S a$, which makes it possible to calculate its elevation $\varphi$ with respect to the horizontal plane, and the relative azimuth $A Z$. The field of view FOV from left to right covers about $52^{\circ}$ and corresponds to an estimated FD of $37 \mathrm{~mm}$. FD is proportional to the distance of the camera to the photographic plane. The vertical direction makes an angle $\alpha$ (camera's pitch angle) with the camera's upward direction, and an angle $\theta$ with $L S a$ direction. $L S a$ 's elevation $\varphi=90^{\circ}-\theta$. Trigonometric calculations give an elevation of about $28^{\circ}$ relative to the horizon, i.e. about $14^{\circ}$ below the expected position of the sun, and $35^{\circ}$ of horizontal azimuth behind the camera (see also figure 12).

$2^{\circ}$ Estimation of the center of view $\mathrm{C}$ to which the camera points, and the horizon line $\mathrm{H}$. C appears to be slightly under $\mathrm{H}$, indicating a slightly tilt camera with the pitch angle $\alpha$. Figures 10 and 11 explain this step.

$3^{\circ}$ Estimation of FD, the Focal Distance ${ }^{30}$ (Fig. 11) chosen by Ruah. From the perspective distortions of the heads of the boy and the girl in D115's

30 We use the conventional Focal Length or Distance (FD), corresponding to a standard film width of $36 \mathrm{~mm}$. 
sides, FD appears to be between 31 and $46 \mathrm{~mm}$. "Press Photography" book [Kinkaid 1936,10] suggests to avoid artistic effects and to choose FD greater than $37 \mathrm{~mm}$, recommending $44 \mathrm{~mm}$ (translated in modern units). From the shadows seen on the two mentioned persons, we estimated the Field of View (FOV) $\sim 50^{\circ}$. This gives FD $\sim 37 \mathrm{~mm}$. Figure 11 shows how the calculations of elevation $\varphi$ and the relative azimuth $A Z$ are performed. We obtain the following estimations of $\varphi$ for various values of FD.

\begin{tabular}{|c|c|c|c|c|c|}
\hline $\begin{array}{c}\text { Focal Length } \\
\text { FD }(\mathrm{mm})\end{array}$ & $\begin{array}{c}\text { Elevation } \\
\varphi\left(^{\circ}\right)\end{array}$ & $\begin{array}{c}\text { Rel. Azimuth } \\
A Z\left(^{\circ}\right)\end{array}$ & $\begin{array}{c}\text { Pitch Error } \\
\text { Factor } \varepsilon\end{array}$ & $\begin{array}{c}\text { Roll Error } \\
\text { Factor } \omega\end{array}$ & $\begin{array}{c}\text { Field of View } \\
\text { FOV }\left(^{\circ}\right)\end{array}$ \\
\hline 30 & 31.859 & 41.055 & 0.754 & 0.653 & 61.928 \\
\hline 33 & 30.241 & 37.992 & 0.788 & 0.613 & 57.221 \\
\hline 37 & 28.238 & 34.511 & 0.824 & 0.565 & 51.885 \\
\hline 45 & 24.752 & 29.081 & 0.874 & 0.485 & 43.603 \\
\hline
\end{tabular}

Thus, for D115 realistic focal length values, we estimate $\varphi$ between $25^{\circ}$ and $32^{\circ}$, which is $10^{\circ}$ to $17^{\circ}$ lower than the expected $42^{\circ}$ for the sun. These estimates confirm the impression of eyewitnesses at the Cova and up to tens of $\mathrm{km}$, of a falling "sun" towards the ground. The error factors $\varepsilon$ and $\omega$ give the ratio between the $\varphi$ elevation estimated error, and the camera pitch and roll angles estimation errors $(\varepsilon=\cos (A Z) ; \omega=-\cos (\alpha) \sin (A Z)$; see explanation below in Mathematical analysis).

Those results can be further visualized with Blender ${ }^{\circledR}$ 3D simulation software, by adding at the camera position, a second virtual camera of fixed focal length. This virtual camera is positioned horizontally in order to display the horizontal coordinates system on a transparent HUD (Head-Up Display). The vanishing point $V P a$ ("Antisolar point", opposite to $L S a$ ) is located at spherical coordinates $[-\varphi ;-A Z]$ showing a graphical solution of 


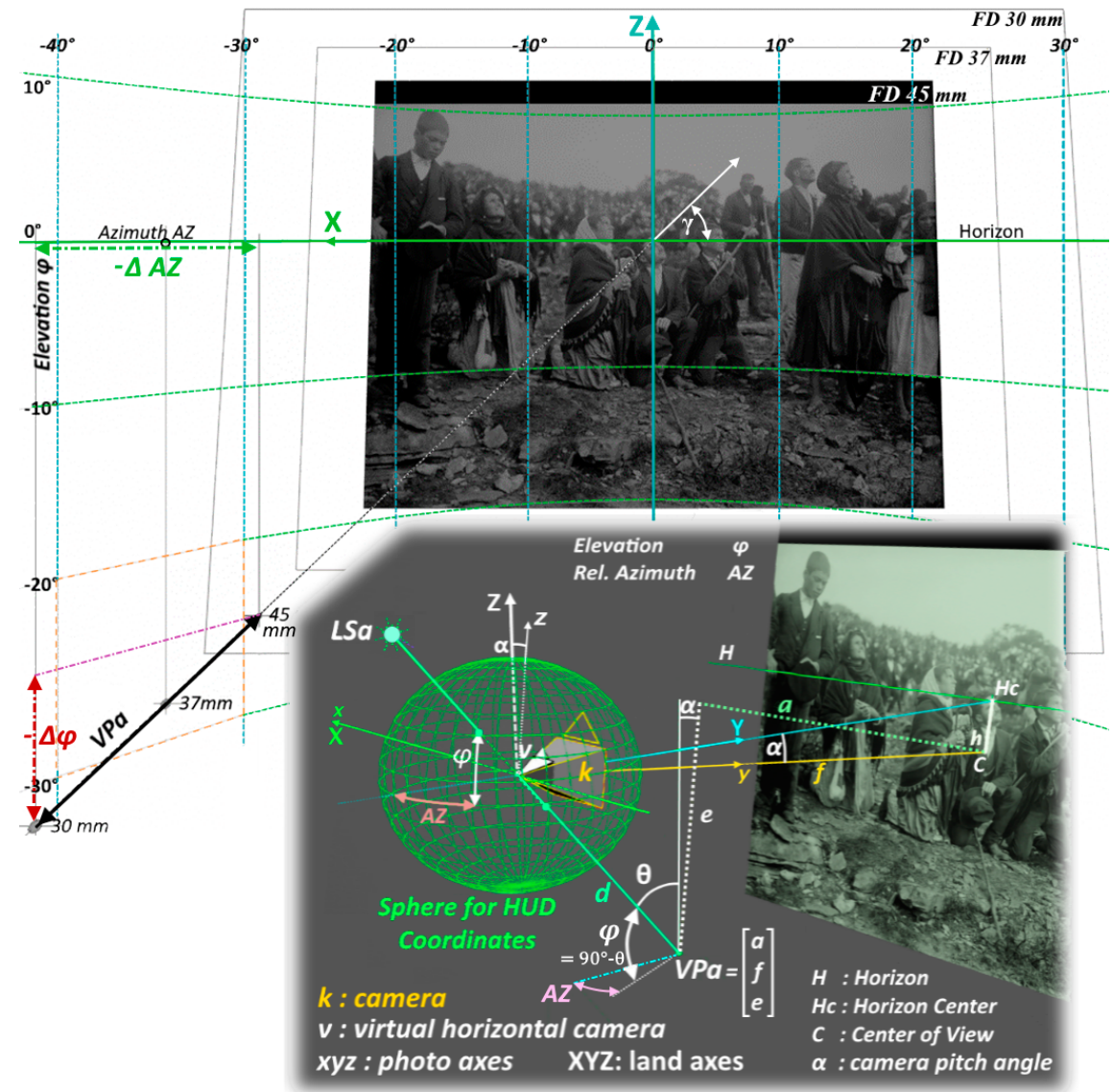

Figure 12. Graphical estimation of $L S a$ 's horizontal spherical coordinates $[\varphi ; A Z]$ (elevation $\varphi$ and relative azimuth $A Z$ ) opposite to its vanishing point $V P a([-\varphi ;-A Z])$. Below: Geometrical view. $[\varphi ; A Z]$ estimates depend on the evaluation of FD. A virtual camera $v$ positioned horizontally, is linked to the camera $k$, with a wired HUD virtual sphere, displaying the spherical coordinates of the Cova da Iria. Above: View from the camera $v$ for FD=30 to $45 \mathrm{~mm}$. $H c$ and $C$ are fixed. $V P a$ is in the photographic plane out of the photo (which appears trapezoidal for non-zero $\alpha$ ). The locus of $V P a$ is quasi linear, with a slope angle approaching $\gamma$, the perspective projection of $\varphi$ at $H c$. Note the perspective distortions at wide angles, in the projections of HUD sphere's $10^{\circ} \times 10^{\circ}$ areas on the camera's view plane (the dotted wire mesh). [Note: the chosen $x y z$ and XYZ systems are indirect (left handed). In our Blender simulation they are right handed.] 
the calculations (see Figure 12, with FD $=30$ to $45 \mathrm{~mm}$ ) $^{31}$. This chart visually confirms the calculations in the above table.

\section{Mathematical analysis ${ }^{32}$}

This section presents the formulas to evaluate $L S a$ 's elevation $\varphi$ and azimuth $A Z$, and the effects on $\varphi$ of the main sources of errors: in the focal length FD, in the camera's pitch angle $\alpha$ (linked to $h$, the distance of the center of view $\mathrm{C}$ to the horizon line $\mathrm{H}$ ), and in the camera's roll angle $\beta$ (linked to errors in the estimation of the horizontality of $\mathrm{H}$ ). We already analyzed the effect of an error in FD estimation, with $\varphi$ varying between $25^{\circ}$ and $32^{\circ}$ as FD varies between 45 and $30 \mathrm{~mm}$. We analyze first the effect of a pitch error $\delta \alpha$ on $\varphi$.

As the camera's shadow is casted on the vanishing point $V P a$, the direction of $L S a$ is given by the difference between the camera position and $V P a: L S a D i r=[C a m-V P a]$. Choosing the Camera's Cartesian coordinate $x y z$ system for the simulation on fig. 12 (Cam is at the origin), the $(x, y, z)$ coordinates of the parametrical vectors are ${ }^{33}$

$$
\text { LSaDir }=-V P a=-(a, f, e)^{T} \quad H c=(0, f, h)^{T}
$$

31 One can simply add some position and rotation tracking constraints to the second camera when changing FD. Blender automatically positions the photographic plane and $\mathrm{VPa}$ in a 3D space. $V P a$ 's coordinates are read on the HUD. Figure 12 shows that the locus of $V P a$ vs FD is a line that approaches the central point Hc on the horizon, when FD tends towards infinity. We used Blender ${ }^{\circledR}$ 3D software version 2.91 (November 25th 2020): https://www.blender.org/download/releases/2-91/.

32 The interested reader will find a detailed explanation and videos of Blender ${ }^{\circledR}$ simulations on https://sites.google.com/pusc.it/elevation-azimuth/home (under construction on February 11,2021$)$.

33 In our Blender simulation, the focal distance FD is proportionally locked to the distance $f$ of the camera to the photographic plane. This fixes the dimensions of the viewed photo and of $a, e$ and $h$ (the constant parameters given by the geometrical analysis of the photo). The choice of the scale factor is arbitrary. We choose 0.1 for an easy reading and setting of FD. However, the scale of the photo must first be matched so that the photo width $=3.6$ (so that $f=1.8$ or $\mathrm{FD}=18 \mathrm{~mm}$, corresponds to $\mathrm{FOV}=90^{\circ}$ ). This scaling also sets our estimated positions of $\mathrm{VPa}$ and $\mathrm{Hc}$ (the estimation steps 1 and 2). In D115, we estimated $a=2.4207$, $e=-1.9927$ and $h=0.31$. 
Where ${ }^{T}$ expresses the transpose operator (to get column vectors). The length of LSaDir is

$$
d=\sqrt{a^{2}+e^{2}+f^{2}}
$$

If the camera is horizontal, $h=0, \alpha=0^{\circ}, H c$ and $C$ merge at the center of the photograph, and $L S a$ 's elevation is given by

$$
\varphi_{0}=\operatorname{asin}\left(\frac{-e}{d}\right)
$$

However, when $h>0$, the horizontal system XYZ results from the rotation of the $x y z$ coordinate system by $-\alpha$ (the pitch angle) about the $\mathrm{x}$-axis. The rotation matrix $M(\alpha)$ is:

$$
M(\alpha)=\left(\begin{array}{ccc}
1 & 0 & 0 \\
0 & \cos (\alpha) & \sin (\alpha) \\
0 & -\sin (\alpha) & \cos (\alpha)
\end{array}\right) \quad \text { with } \alpha=\operatorname{atan}(h / f)
$$

$M$ is used to express LSaDir's coordinates in the horizontal system XYZ (see Fig. 12). As in equation (3), the Z component of the vector (M*LSaDir) determines $L S a$ elevation $\varphi$ in function of $\alpha$ (or of $h$ making use of (4) and (2)):

$$
\begin{aligned}
& \varphi=\operatorname{asin}\left(\frac{f \sin (\alpha)-e \cos (\alpha)}{d}\right)=\operatorname{asin}\left(\frac{(h-e) \cos (\alpha)}{\sqrt{a^{2}+e^{2}+f^{2}}}\right)= \\
& =\operatorname{asin}\left(\frac{f(h-e)}{\sqrt{\left(a^{2}+e^{2}+f^{2}\right)\left(h^{2}+f^{2}\right)}}\right) \\
& A Z=\operatorname{atan}\left(\frac{a}{f \cos (\alpha)+e \sin (\alpha))}\right)=\operatorname{atan}\left(a \frac{\sqrt{h^{2}+f^{2}}}{f^{2}+e h}\right)
\end{aligned}
$$

with $0 \leqslant \varphi \leqslant 90^{\circ}$ and $-90^{\circ} \leqslant A Z \leqslant 90^{\circ}$ (when $L S a$ is behind the camera). 
When $h=0$, equation (5) matches (3), and (6) reduces to $A Z=\operatorname{atan}(a / f)$. To evaluate the elevation error $\delta \varphi$ due to some pitch estimation error $\delta \alpha$, we compute the partial derivative of $\varphi(\alpha)$ :

$$
\varepsilon=\frac{\partial \varphi}{\partial \alpha}=\frac{1}{\sqrt{1+\left(\frac{a}{f \cos (\alpha)+e \sin (\alpha)}\right)^{2}}}=\cos (A Z)
$$

The ratio $\delta \varphi / \delta \alpha$ of small errors is about $\partial \varphi / \partial \alpha=\varepsilon$, the pitch error factor equal to the cosine of the relative azimuth $A Z$. So, the magnitude of the $\varepsilon$ factor is less than one and the magnitude of the elevation error $\delta \varphi$ is less than the pitch angle error $\delta \alpha$. Values of $\varepsilon$ are shown in the table above.

Similarly, for the effect of the roll angle error $\delta \beta$ on the elevation estimation error $\delta \varphi$, we first evaluate the elevation $\varphi(\beta)$ :

$$
\varphi=\operatorname{asin}\left(-\frac{E(\beta)}{d}\right)
$$

$E(\beta)$ is the $\mathrm{Z}$ component of the vector $\left(M^{*} N^{*} L S a D i r\right)$ where $M$ is the former $\alpha$ pitch rotation matrix and $N$ is the $\beta$ roll rotation matrix about the camera's y-axis:

$$
\begin{aligned}
& N(\beta)=\left(\begin{array}{ccc}
\cos (\beta) & 0 & -\sin (\beta) \\
0 & 1 & 0 \\
\sin (\beta) & 0 & \cos (\beta)
\end{array}\right) \\
& \varphi=\operatorname{asin}\left(\frac{f \sin (\alpha)-a \sin (\beta) \sin (\alpha)-e \cos (\beta) \cos (\alpha)}{d}\right)
\end{aligned}
$$

When $\beta=0$, equation (9) reduces to (5). The error factor $\omega \sim \delta \varphi / \delta \beta$ at $\beta=0$, is given by the partial derivative of $\varphi(\beta)$ :

$$
\omega=\frac{\partial \varphi}{\partial \beta}(\beta=0)=\frac{-\cos (\alpha)}{\sqrt{1+\left(\frac{f \cos (\alpha)+e \sin (\alpha)}{a}\right)^{2}}}=-\cos (\alpha) \sin (A Z)
$$


The magnitude of the roll error factor $\omega$ is also less than one. The camera's roll angle $\beta$ was assumed to be almost $0^{\circ}$ because common photographic tripods used some spirit level or plumb line to facilitate tuning. Judah Ruah levelled his tripod. Besides, the vertical threads hanging from the fringe of the clothes of the three women in D115 visually confirm a correct vertical tuning when compared with the projected HUD vertical direction ${ }^{34}$. Other $\beta$ error may come from the scanning frame angle of the digitized photo. However, examination of the borders of the digitized D115 shows a few pixels of error on the full width of 6144 pixels, adding at most an insignificant $0.05^{\circ}$ contribution to the error $\delta \beta$.

An elevation analysis at $H c$, the horizon center, makes our conclusions more obvious. Noting $b=|(h-e) a|$, the angle $\gamma$ of the projected elevation at $\mathrm{Hc}$ (see Fig. 12) is given by

$$
\gamma=\operatorname{atan}(b \cos (\alpha))=\operatorname{atan}\left(b \frac{f}{\sqrt{f^{2}+h^{2}}}\right) \leq \operatorname{atan}(b)=43.57^{\circ}
$$

As $b=0.951$ in D115, it happens that the maximum value of $\gamma$ is very near the expected sun's elevation $\left(\sim 42^{\circ}\right)$. The elevation would indeed be $\gamma$ if $|A Z|=90^{\circ}$. However, $|A Z|$ is definitely smaller ${ }^{35}$. Thus the actual elevation must be significantly smaller than $\gamma$ or the expected sun's elevation. This perspective effect is easy to evaluate. As $a=d \cos (\varphi) \sin (|A Z|)$, using (2), (5) and (11), we get: $\tan (\varphi)=\sin (\varphi) / \cos (\varphi)=\tan (\gamma) \sin (|A Z|)$, and

$$
\varphi=\operatorname{atan}(\tan (\gamma) \sin (|A Z|))=\operatorname{atan}(b \cdot|\omega|) \ll 43.57^{\circ}
$$

34 However, the shawl of the kneeled woman on the left seems less protected from a gentle wind, showing a slight dispersion in the thread directions. Best vertical estimate is given by the woman's shawl on the right. Using Blender ${ }^{\circledR}$ simulations, those hanging threads visually fit the vertical direction for FD values between 33 and $39 \mathrm{~mm}$, confirming our estimated $37 \mathrm{~mm}$ value.

$35|A Z|$ is $90^{\circ}$ when $L S a$ and $V P a$ are oppositely located at infinity in the photographic plane and $f<<a, e$. In that case, the girl on the right would have $L S a$ behind her and she would be completely in shadow. 
The roll error factor $\omega(\sim 0.48 \ldots 0.66$, see table above) gives us an idea of the perspective lowering correction we should apply to $\gamma$, the apparent elevation at $H c$, to estimate the actual elevation $\varphi$ (we have $\tan (\varphi) \sim 0.46 \ldots 0.63$ or $\left.\varphi \sim 24.7^{\circ} \ldots .32^{\circ}\right)$. In fact, for a fixed $h=0.31$, the calculated $\varphi$ never reaches $42^{\circ}$ even with an estimated FD $\ll 18 \mathrm{~mm}^{36}$.

The analysis shows that elevation estimation errors can hardly exceed a few degrees. Given a margin of 10 to $17^{\circ}$ between $L S a$ 's and the expected sun's elevations, and the magnitudes of $\varepsilon$ or $\omega$ factors being less than one, inaccuracies do not seem to be able to call into question the lower elevation of $L S a$.

\section{Conclusions}

A careful analysis of the pictures of the "miracle of Fatima" confirms with high probability important assertions of the eyewitnesses. The agreements between photos, testimonies, and recorded data, call into question all the proposed interpretations, whether psychological, meteorological, or physiological. Analyzing picture D115, we identified several key points:

1) The crowd experienced persistent rain until just before the event at solar noon.

2) Clothes dried fast printing IR shadows (wet parts bordered by dried areas).

3) There were two main light sources of similar brightness casting faint shadows: maybe a small cloud overhead, and a pale "sun".

4) Shadows are mostly fuzzy but accurate on sloped surfaces or under objects.

5) The ambiance was subdued and tinged, as the deep darkness of the double shadows shows.

6) Distant testimonies locate the event in the Fatima direction, not the sun direction.

36 This gives unrealistic values and strong perspective distortions. The estimated $\varphi$ reaches a maximum of $41.94^{\circ}$ when $\mathrm{FD}=9.86 \mathrm{~mm}\left(\alpha=17.4^{\circ} ; A Z=81.9^{\circ} ; \omega=0.945 ; \varepsilon=0.14\right)$. 
7) the sun-like source cannot be the sun: calculations from its shadows and vanishing point, estimate the elevation between $25^{\circ}$ and $32^{\circ}$, not the expected $42^{\circ}$.

Our evaluation of the position of light sources is based on some estimates (vanishing point, horizon, center of view, field of view, and focal length). We concluded our analysis with a summary of our mathematical analysis to evaluate $L S a$ 's elevation and relative azimuth. This allows us to estimate the main sources of errors. Inaccuracies in estimates widen the confidence interval of the results without calling into question our conclusions.

\section{Future and possible research}

We plan further similar analysis of other photographs, and on innovative techniques to estimate or detect sky brightness maps. For example, Mixed or Augmented Reality software use database trained deep learning systems, to correct shaded illumination of inserted virtual objects ${ }^{37}$. However, these advanced technologies cannot easily be applied to the soft shadows of the Fatima pictures. Researchers report the limits of accuracy and the numerous difficulties of detecting light sources in similar cases and present images or videos of shaded objects more suitable for large automated mathematical processing (Kan 2019; Sanghyun 2018; Malawski 2018; Bunteong and Chotikakamthorn 2016; Whelan et al. 2016; Kolivand et al. 2015; Li et al. 2014; Aittala 2010; Lalonde, Efros and Narasimhan 2009). Moreover, these researchers often restrict their analysis to a visually coherent shadowing, without seeking precise information. The estimated positions of the sources by these automatic processes often exhibit errors of $5^{\circ}$ to $20^{\circ}$ for pictures of far better quality than Fatima pictures. More precision often requires a visual correction of the estimates by a specialist, so these programs are used as an assistant in difficult cases.

BAD-SLAM, DeepLight, Apple ARKit, Microsoft Hololens, Google Glass, Immersive 3D Solutions, etc. 


\section{Acknowledgements}

We thank the services of the Sanctuary of Fatima, especially Dr. Marco Daniel Duarte (Head of Fatima Shrine's Research Department) and Mr. André Melicias (Coordinator of the Archives and Library of the Sanctuary of Fatima), as well as Mrs. Maria Ana Marqués - Van Huylenbroek, for their help and the valuable data they provided for this work. I am grateful to Mr. Matthew Venoit for his help with the English translation and the providential encouragement of so many others whom I find difficult to name here.

\section{References}

Abdellah, Marwa M., Engy M. Mostafa, Mohamed A. Anber, Islam S. El Saman, and Mohammed E. Eldawla. 2019. "Solar maculopathy: prognosis over one year follow up.” BMC Ophthalmol 19: 201. DOI: 10.1186/s12886-019-1199-6

Aittala, Miika. 2010. "Inverse lighting and photorealistic rendering for augmented reality.” The Visual Computer 26(6-8): 669-678.

Archbold, Matthew. 2016. "Top 10 "Scientific" and Hilarious Explanations for the Miracle at Fatima.” National Catholic Register, https:/www.ncregister.com/ blog/top-10-scientific-and-hilarious-explanations-for-the-miracle-at-fatima

Barthas, Casimir. 1957. Fatima, merveille du XXe siècle. Toulouse: Fatima-éditions.

Barthas, Casimir. 1969. Fatima, 1917-1968. Histoire complète des apparitions et de leurs suites. Fatima-éditions: Toulouse.

Brochado, Costa. 1955, Fatima in the light of History. Milwaukee: Bruce.

Blom, Jan D. 2010. A Dictionary of Hallucinations. New-York: Springer Verlag.

Bunteong, Anusorn, and Nopporn Chotikakamthorn. 2016. "Light source estimation using feature points from specular highlights and cast shadows.” International Journal of Physical Sciences 11: 168-177. DOI: 10.5897/IJPS2015.4274

Cambpell, Steuart. 1989. “The 'Miracle' of the Sun at Fatima.” Journal of Meteorology 14(142): 333-338, http://www.ijmet.org/wp-content/uploads/2014/09/142.pdf

Chalupsky, Mary. 2017. "Bishop at Mass recalls aunt's story of being at Fatima for miracle of sun.” The Pilot, https://thebostonpilot.com/article.asp?Source=Trending \&ID $=180544$

Coelho Cristino, Luciano, and Ana Teresa dos Santos Silva. 2013. Documentação crítica de Fátima: Seleção de documentos (1917-1930), Santuario de Fátima, accesible at http://www.fatima.pt/files/upload/fontes/F001_DCF_selecao.pdf 
Cowley, Les. 2020. “Atmospheric Optics”, Website, https://www.atoptics.co.uk/halo/ dogalt.htm, https://www.atoptics.co.uk/halo/dogfm.htm, https://www.atoptics. co.uk/halo/parhelia.htm, accessed 12 Nov. 2020.

de Montmollin, Germaine. 1956. "L'effet autocinétique comme phénomène et comme instrument.” L'année psychologique 56(2): 461-474, DOI: 10.3406/psy.1956.8887

Gomes, João Fr. 2017. "Fátima. 13 testemunhos de quem esteve no dia do 'milagre do Sol.” Observador, https://observador.pt/especiais/fatima-13-testemunhosde-quem-esteve-no-dia-do-milagre-do-sol.

Haffert, John M. 2006. Meet the witnesses of the miracle of the Sun. Pennsylvania: TFP, Spring Grove.

Hope-Ross, Monique, Stephen Travers, and David Mooney. 1988. “Solar retinopathy following religious rituals.” British Journal of Ophthalmology 72: 931-934

Jacobson, Reginald E., Sidney F. Ray, Geoffrey G. Attridge, and Norman R. Axford.. 2000. The Manual of Photography. Photographic and digital imaging, $9^{\text {th }}$ ed., Waltham: Focal Press.

Jaki, Stanley L. 1999. God and the Sun at Fatima. New Hope: Real View Books.

Jaki, Stanley L. 2000. The Sun's Miracle, or of Something Else?, New Hope: Real View Books.

Jenkins, Rob, and Christine Kerr. 2013. "Identifiable Images of Bystanders Extracted from Corneal Reflections.” PLOS ONE. DOI: 10.1371/journal.pone.0083325

Källmark, Fredrik P., and Jan Ygge. 2005. "Photo-induced foveal injury after viewing a solar eclipse.” Acta Ophthalmol. Scand. 83: 586-589. DOI: 10.1111/j.16000420.2005.00511.x

Kán, Peter, and Hannes Kafumann. 2019. “DeepLight: light source estimation for augmented reality using deep learning.” Visual Computer 35: 873-883. DOI: 10.1007/s00371-019-01666-X

Kinkaid, James C. 1936. Press Photography, Boston: American Photographic Publishing Co.

Kolivand, Hoshang, Mohd Sunar, Ismahafezi Ismail and Mahyar Kolivand. 2015. “Fuzzy Soft Shadow in Augmented Reality Systems.” Borneo Science 36(2): 8-18. http://borneoscience.ums.edu.my/?p=1795

Können, Gunther P. 1985. Polarized Light in Nature. Cambridge: CUP.

Lalonde Jean Fr., Alexei A. Efros, and Srinivasa G. Narasimhan. 2009. "Estimating natural illumination from a single outdoor image.” 2009 IEEE 12th International Conference on Computer Vision, Kyoto, 183-190, DOI: 10.1109/ICCV.2009.5459163.

Li, Dan, Bin Xiao, Yingsong Hu, and Ruizhang Yang. 2014. "Multiple linear parameters algorithm in illumination consistency." Proceeding of the 11th World 
Congress on Intelligent Control and Automation, 5384-5388. DOI: 10.1109/ WCICA.2014.7053633

Malawski, Filip. 2018. “Driver Assistance System Using Augmented Reality Headset.” 2018 41st International Conference on Telecommunications and Signal Processing (TSP), Athens, 1-4. DOI: 10.1109/TSP.2018.8441298.

Meessen, August. 2005. “Apparitions and Miracles of the Sun.” Actas do Forum International, Centro Transdisciplinar de Estudos da Consciência, Consciências 2, Eds. J. Fernandes, N.L. Santos, 199-222.

Meinel, Aden, and Marjorie Meinel. 1983. Sunsets, Twilights and Evening Skies. Cambridge: CUP.

Morujão, Isabel. 2017. “As Aparições de Fátima relatadas por carta: redes sociais e familiares da espiritualidade mariana.” Via Spiritus 24: 5-49.

Mwanza, Jean-Claude K., David L. Kayembe, Dieudonné K. Kaimbo, Paul M. Kabasele, and D. K., Ngoy. 2000. "Rétinopathie solaire acquise durant des séances de prière.” Bull. Soc. Belge Ophtalmol 275: 41-45.

Nickel, Joe. 1993. Looking for a Miracle. Weeping Icons, Relics, Stigmata, Visions and Healing Cures. New York: Prometheus Book.

Peres, Michael R. 2007. The Focal Encyclopedia of Photography, $4^{\text {th }}$ ed., Amsterdam: Elsevier.

Pires, Catarina. 2016. “A surpreendente história da família Ruah.” Noticias Magazine, Lisboa, 11 apr., https://www.noticiasmagazine.pt/topico/samuel-ruah/

Radford, Benjamin. 2013. “The Lady of Fatima \& the Miracle of the Sun.” Live Science, May 02, https://www.livescience.com/29290-fatima-miracle.html

Radford, Benjamin. 2019. “Fatima Miracle Claims All Wet.” Skeptical Inquirer 43(3) May/June, https:/skepticalinquirer.org/2019/05/fatima-miracle-claims-all-wet/ Reis, Bruno Cardoso. 2001. “Fátima: A Recepção Nos Diários Católicos (1917-1930).” Análise Social 36(158/159): 249-299. http://www.jstor.org/stable/41011505.

Seo, Sanghyun, Dongwann Kang, and Sangoh Park. 2018. "Real-time adaptable and coherent rendering for outdoor augmented reality.” J. Image Video Proc., 1-8. DOI: 10.1186/s13640-018-0357-8

Sheemar, Abhishek, Brijesh Takkar Shreyas Temkar, and Pradeep Venkatesh. 2017. "Solar retinopathy: the yellow dot and the rising sun." BMJ Case Reports, DOI: 10.1136/bcr-2017-222690.

Simons, Paul. 2005. "Weather Secrets of Miracle at Fátima.” The Times, 17 February. Tape, Walter. 1994. "Atmospheric Halos.” American Geophysical Union, Antarctic Research Series 64.

Tape, Walter, and Jarmo Moilanen. 2006. Atmospheric Halos and the Search for Angle $x$. Washington, D.C.: American Geophysical Union. 
Thornton, Donal. 2009. “Irish Catholic pilgrims ‘blinded' by the light at Knock shrine to Virgin Mary.” Irish Central News, https://www.irishcentral.com/news/pilgrimsmay-be-blinded-by-the-light-at-marys-shrine-in-ireland-78307647-237673041

Transancos, Stacy. 2013. “Skeptic Benjamin Radford on the Fátima Miracle.” StrangeNotions.com, https://strangenotions.com/skeptic-benjamin-radford-on-the-fatima-miracle/

van den Aardweg, Gerard J.M. 1988. Fatima, 1917, de grootste paranormale gebeurtenis uit de moderne geschiedenis. Brugge: Tabor.

Wade, Nicholas J., and Dieter Heller. 2003. "Visual Motion Illusions, Eye Movements, and the Search for Objectivity." Journal of the History of the Neurosciences: Basic and Clinical Perspectives 12(4): 376-395. DOI: 10.1076/jhin.12.4.376.27911

Weng, Christina Y., Jennifer Lim, Luis Ignacio Larrazabal, and Ross Bronson Chod. 2020. “Solar Retinopathy.” Eyewiki Encyclopedia, American Academy of Ophtalmology, https://eyewiki.aao.org/Solar_Retinopathy

Whelan, Thomas, Renato F. Salas-Moreno, Ben Glocker, Andrew J. Davison, and Stefan Leutenegger. 2016. "Elasticfusion: real-time dense slam and light source estimation.” Int. J. Robot Res. 35(14): 1697-1716.

Wirowski Artur. 2012. "Modelling of the Phenomenon Known as "the Miracle of the Sun" as the Reflection of Light from Ice Crystals Oscillating Synchronously.” Journal of Modern Physics 3(3): 282-289. DOI: 10.4236/jmp.2012.33040.

Wirowski, Artur, and Paweł Szczerba. 2019. "Derivation of equations of the model of the dynamic behaviour of the three-dimensional atmospheric cloud of electrically charged ice crystals under the influence of electrostatic forces.” Meccanica 54: 1703-1715, DOI: 10.1007/s11012-019-01044-w 